\begin{tabular}{|c|c|c|}
\hline ב & $\begin{array}{l}\text { International Journal of Current Research in } \\
\text { Biosciences and Plant Biology }\end{array}$ & $=$ \\
\hline & Volume 8 • Number o6 (June-2021) • ISSN: 2349-8080 (Online) & \\
\hline $\begin{array}{l}\text { EXCELLENT } \\
\text { PUBLISHERS }\end{array}$ & Journal homepage: www.ijcrbp.com & \\
\hline
\end{tabular}

Original Research Article

doi: $\underline{\text { https://doi.org/10.20546/ijcrbp.2021.806.003 }}$

\title{
Rapid screening for minimum inhibitory concentration of medicinal plant extracts against human pathogenic bacteria
}

\author{
K. Arivalagan and M. Prakash (iD* \\ Research Department of Microbiology, Kanchi Shri Krishna College of Arts and Science, \\ Kilambi, Kanchipuram, Tamil Nadu 631551, India \\ *Corresponding author; e-mail: mprakashmicro@gmail.com
}

\begin{abstract}
Article Info
Keywords:

Antibacterial screening

Crude extracts

Medicinal plants

Pathogenic bacteria

Resazurin dye reduction

Abstract

In the present study, crude extracts of different parts of six medicinal plant species have been screened for antibacterial activity through resazurin dye reduction assay. The crude extracts of Coleus strobilifer, Phyllanthus reticulatus, Acalypha paniculata, Solanum erianthum, Curculigo orchioides, and Spatholobus parviflorus were prepared with the solvents, petroleum ether, methanol and ethanol by Soxhlet extraction method. Resazurin titreplate assay was done for screening the plant extracts for minimum inhibitory concentration (MIC) the pathogenic bacteria, Staphylococcus aureus, Pseudomonas aeruginosa and Klebsiella pneumoniae. The results revealed that the crude extracts of various parts of the plants obtained using three different solvents were capable of inhibiting the test bacteria with the MIC values ranging from $125 \mu \mathrm{L}$ to $>1000 \mu \mathrm{L}$. The stem extracts of $C$. strobilifer and A. paniculata showed the least antibacterial activity with the MIC values $>1000 \mu \mathrm{L}$. The leaf extracts of $S$. erianthum showed a MIC value of 250-500 $\mu \mathrm{L}$ against $S$. aureus, P. aeruginosa and $K$. pneumoniae. The results revealed that the rhizome extract of $C$. orchioides and fruit extracts of $S$. parviflorus have good antibacterial activity and can be tested further with specific trials to develop antibacterial drugs. For initial screening of medicinal plants for antibacterial activity is faster, more accurate and reliable with resazurin dye reduction method.
\end{abstract}

- Received: 10 April 2021 • Revised: 22 May 2021 • Accepted: 30 May 2021 • Published Online: 06 June 2021

\section{Introduction}

According to the estimate of National Medicinal Plants Board, more than 7000 species of higher plants have been utilized medicinally to treat various ailments (IMP, 2021). Natural products derived from higher plants may contribute to the search for new drugs by indicating new modes of pharmacological action. The recent studies also impart the identification and isolation of new therapeutic compounds of medicinal importance from the higher plants for specific diseases. On the other hand, the control of pathogenic micro-organisms is a big question because they have developed resistance for synthetic and semi-synthetic drugs. It is the right time to bridge the gap between these two phenomena for the benefit of human beings. Drug resistance is a growing public health threat with pathogenic organism quickly bearing to cope with the challenges posed by therapeutic agents. When the antibiotic penicillin was discovered some fifty years ago, it was considered as a 
miracle drug of the century. This scene has suddenly changed with the development of resistance among bacteria and the whole world is now confronted with rapidly emerging drug resistant bacteria (Ventola, 2015; Aslam et al., 2018; Yau et al., 2021). As a result, resistance to antibiotic treatment is a common phenomenon among bacteria of every possible infection. Hence attempts are being made to produce more effective antibiotics.

It is well known fact that the medicinal plants are the resources of promising drugs for many diseases. The biological and pharmacological properties of many plants are still unknown. World-over, the scientists are exploring the possibilities of utilizing or finding out pharmacologically active compounds from medicinal plants. For example, screening of medicinal plants for their phytochemicals, antioxidant, anticancer and antimicrobial activities is the prime concern for finding out an effective phytochemically active principle (Salehi et al., 2020; Kausar et al., 2021; Kauroo et al., 2021). Researchers have reported the antimicrobial activity of various ethnomedicinal plants using different solvents and they mainly concentrate on antimicrobial activity of individual plant or plant parts. However, many of the locally used ethnomedicinal plants are not known for their effectiveness in controlling pathogenic bacteria. For this, there is a necessity to screen the medicinal plants as a preliminary trial for their antimicrobial activity so as to go ahead for effective plants for the confirmatory studies and drug development. Hence, the ethnomedicinal plants locally used by ethnic communities and rural folks need to be given urgent attention to find suitable antimicrobial agents. A new high throughput antibacterial method employing the dye resazurin as an indicator of bacterial growth was developed to assess drug resistance and sensitivity by combined measurements of microtitreplates and colorimetric assays (Karuppusamy and Rajasekaran, 2009). Therefore, the present study has been aimed to screen six different enthnomedicinal plant species for their antibacterial activity against pathogenic bacteria through resazurin dye reduction test.

\section{Materials and methods}

Based on the availability and ethnomedicinal utility, six species of plants were selected for the study. The plants were collected from Servarayan hills, Salem, identified and transported to the laboratory for further processing. The plants and parts collected and used for the present study are presented in Table 1 and Fig. 1 . The collected parts of the plants, $C$. strobilifer, $P$. reticulatus, A. paniculata, $S$. erianthum, $C$. orchioides and $S$. parviflorus were shade dried for a week and powdered using mortar and pestle. A fine powder obtained was stored in air tight poly bags and used for the preparation of extract. The dried powder was filled in Soxhlet apparatus and extracts were prepared using petroleum ether (PET-E), methanol (METH) and ethanol (ETH) as solvents. For extraction, the powdered plant material of $100 \mathrm{~g}$ was used. The extraction was done for $24 \mathrm{~h}$. With the help of rotary evaporator, the crude extracts were obtained and stored in refrigeration condition for further use.

Table 1. Details of the plants used in the present study.

\begin{tabular}{lll}
\hline Plant name & Family & $\begin{array}{l}\text { Part of the plant used in the present } \\
\text { study }\end{array}$ \\
\hline Coleus strobilifer (Roxb.) A.J.Paton & Lamiaceae & Leaves and stem \\
Phyllanthus reticulatus Poir. & Phyllanthaceae & Leaves and stem bark \\
Acalypha paniculata Miq. & Euphorbiaceae & Leaves and stem \\
Solanum erianthum D.Don. & Solanaceae & Leaves and fruits \\
Curculigo orchioides Gaertn. & Hypoxidaceae & Leaves and rhizome \\
Spatholobus parviflorus (DC.) Kuntze & Fabaceae & Leaves and fruits \\
\hline
\end{tabular}

\section{Antimicrobial activity}

The selected bacterial strains are collected from NCIM (National centre for industrial microorganisms, Chandigarh) .The bacterial species, Staphylococcus aureus, Pseudomonas aeruginosa and Klebsiella pneumoniae were used for the study. For culturing and maintain the bacterial species nutrient broth were prepared. The following medium compositions were used: Beef extract- $3.0 \mathrm{~g}$; Peptone- $2.5 \mathrm{~g}$; NaCl $-1.0 \mathrm{~g}$; Water- $1000 \mathrm{ml}$; pH- 6.0-6.5. Medium compositions were prepared and autoclaved at $15 \mathrm{lbs}$ or $121{ }^{\circ} \mathrm{C}$ for 15 min. Broth were transferred in to test tube culture was transferred in to culture tube. Then the tubes were incubated at $36{ }^{\circ} \mathrm{C}$ and the bacterial growth was observed based on turbidity. 

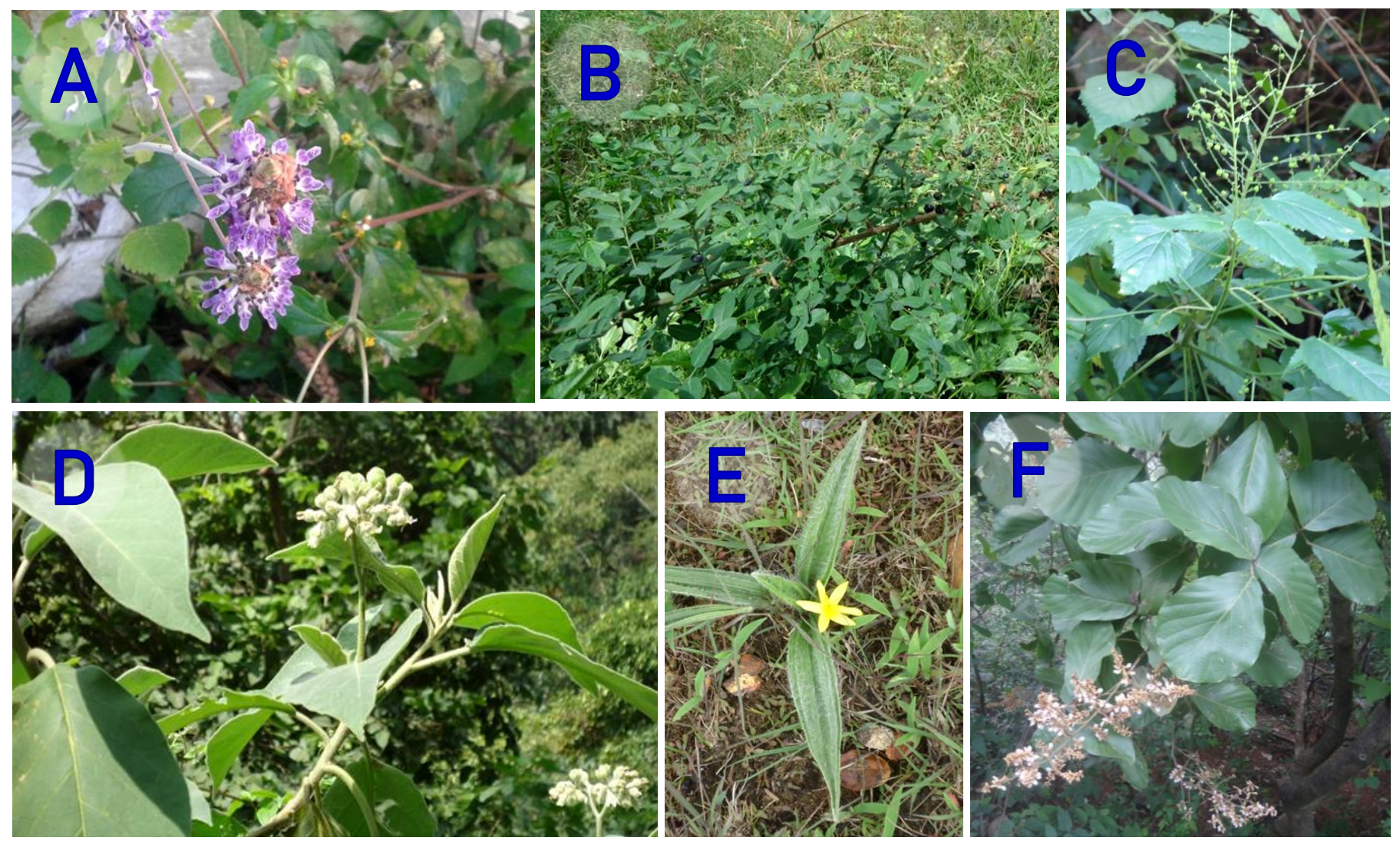

Fig. 1: Plants used for the study. (A) Coleus strobilifer, (B) Phyllanthus reticulatus, (C) Acalypha paniculata, (D) Solanum erianthum, (E) Curculigo orchioides, and (F) Spatholobus parviflorus.

\section{Bacterial strains and culture conditions}

Bacterial strains procured from IMTECH, Chandigarh and cultured on Mueller-Hinton agar media with regular interval for subculture and stored in $20 \pm 2{ }^{\circ} \mathrm{C}$. Stock cultures containing $1 \times 10^{7} \mathrm{cfu} \times \mathrm{mL}(0.5$ MacFarland $)$ of each bacterial strains were saved frozen at $-20^{\circ} \mathrm{C}$, thawed when required to perform the test and grown for 2 days in complete nutrient agar broth. The culture obtained were vortexed, large agglomerates allowed to sediment completely and the supernatant further diluted 1:5 in complete minimal broth titres were determined by viable counting on hemocytometer under microscope, giving $1 \times 10^{3}$ per $\mathrm{mL}$. These strain dilutions were used as inoculum in both microtitre assay and colorimetric assay.

\section{Resazurin dye reduction method}

The antibacterial activity of different solvent extracts of the medicinal plants was determined by resazurin dye reduction method (Kruppusamy and Rajasekaran, 2009) The dye resazurin was obtained from Sigma chemicals and prepared as $10 \mathrm{~g} / \mathrm{L}$ sterile water stock solution, stored in frozen at $-20^{\circ} \mathrm{C}$, thawed and diluted 1:10 in sterile water when required. The titreplate resazurin assay was performed in 96-well plates. Two-fold dilutions of each antibiotics and plant extracts were prepared in the test wells in complete nutrient broth, the final antibiotic concentrations being streptomycin $0.06 \mathrm{mg} / \mathrm{L}$ and tetracycline $0.12 \mathrm{mg} / \mathrm{L}$. Twenty microlitres of each bacterial suspension was added to $180 \mu \mathrm{L}$ of antibiotics and plant extracts containing culture medium. Control wells were prepared with culture medium and bacterial suspension only. The plates were sealed and incubated for $12 \mathrm{~h}$ at $37^{\circ} \mathrm{C}$. After each incubation time, $5 \mu \mathrm{L}$ of resazurin solution were added per well, coloring them blue. The plates were incubated at $37{ }^{\circ} \mathrm{C}$ for additional 5 h. After one hour incubation time intervals plates were read for color change from blue to pink and pink to color less in live-bacterial strains containing wells. Extracts that showed preliminary microtitre-plate assay were 
revealed the fast decoloration of resazurin which extracts did not have antibacterial potential. The bioactivity of the extracts was screened for the extracts that inhibit the dye reduction.

For colorimetric resazurin assay, inoculums were prepared by various dilutions of growing bacterial strains in Mueller-Hinton broth in $10 \mathrm{~mL}$ test tubes. The tubes were sealed and incubated under $37{ }^{\circ} \mathrm{C}$ for $24 \mathrm{~h}$. After the incubation, test tubes were added with various concentrations of the plant extracts prepared in the same broth. Different concentrations tested were: 1000, 500, $250,125,62.5,31.25,15.62$ and $7.81 \mu \mathrm{L}$. Positive controls were prepared with only $9 \mathrm{~mL}$ of broth containing $1 \mathrm{~mL}$ of $0.1 \%$ resazurin solution without plant extracts and antibiotics. Antibiotic control tubes were also maintained with aliquots of antibiotic solutions with respective bacterial strains in serial concentrations. In each test tube, $1 \mathrm{~mL}$ of $0.1 \%$ resazurin solution was added and the tubes were further incubated at $37^{\circ} \mathrm{C}$ for $5 \mathrm{~h}$. After the incubation, $1 \mathrm{~mL}$ of solution were taken out form each test tube and read the absorbancy (OD) at $590 \mathrm{~nm}$ in a spectrophotometer up to $5 \mathrm{~h}$. The minimum inhibition concentration (MIC) was defined as the lowest concentration of the extract that prevent color change in the test tubes as the OD is very close to positive control tube.

\section{Results and discussion}

The resazurin reduction test can be used for colorimetric determination of MIC of the plant extracts on par with earlier methods. After $5 \mathrm{~h}$ of inoculation of sample extracts in different concentrations with marker dye solution were taken the absorbancy of the cultured broth. The color changes in the tubes can be markedly visible and also obtained MIC (maximum absorbancy) for potential antibacterial extracts showed the values close to the antibiotic control wells. The MIC values of $\leq 125 \mu \mathrm{L}$ showed the range of concentration which is equal or close to reference antibiotic concentrations $(62.5 \mu \mathrm{L})$. In most of all the treatments ETH extracts showed higher antibacterial activity with lower MIC values when compared with the PET-E and METH extracts of the medicinal plants used (Table 2). The ETH leaf extracts of $C$. strobilifer showed a MIC of 250 $\mu \mathrm{L}$ followed by $500 \mu \mathrm{L}$ against $K$. pneumoniae, while rest of the extract concentrations showed $>1000 \mu \mathrm{L}$. None of the solvent extracts of $C$. strobilifer stem showed MIC values $<1000 \mu \mathrm{L}$ against the test bacteria.
ETH leaf and ETH stem bark extracts of $P$. reticulates recorded an MIC value of $250 \mu \mathrm{L}$ against $P$. aeruginosa and $S$. aureus, respectively (Table 2). All the solvent extracts of leaf and fruits of $S$. erianthum possessed lower MIC values against the test bacteria; while the ETH fruit extracts showed a least MIC value of $125 \mu \mathrm{L}$ against $K$. pneumoniae. PET=E, METH and ETH leaf extracts of $C$. orchioides showed MIC values above $1000 \mu \mathrm{L}$, whereas the rhizome extract recorded higher antimicrobial activity in terms of low MIC values. PETE fruit extracts of $S$. erianthum showed an MIC value of $250 \mu \mathrm{L}$ against $S$. aureus, $P$. aeruginosa and $K$. pneumoniae; while, it was $125 \mu \mathrm{L}$ for ETH extract against $K$. pneumoniae.

The plants used in the present study, $C$. strobilifer, $P$. reticulatus, A. paniculata, S. erianthum, C. orchioides and $S$. parviflorus are reported to possess different medicinal properties due to the presence of a variety of phytochemical compounds. For instance, $C$. strobilifer is an annual herb with traditional medicinal properties such as antiulcer, expectorant, stimulant and antihepatic agent (Rupali et al., 2020). Similarly, C. orchioides, a native medicinal plant of India, has been used in Ayurvedic system of medicine because it is known to be effective aphrodisiac, immunostimulant, hepatoprotective, antioxidant, anticancer and antidiabetic agent due to the presence of mucilage, phenolic glycosides, saponins and aliphatic compounds (Chauhan et al., 2010).

The plant, $P$. reticulatus is effective medicinal plant for curing several oral complications and helminthiasis (Sharma and Kumar, 2013). The MIC results of the present study showed variable levels of antibacterial activity of the medicinal plant extracts. The medicinal property of various parts of the medicinal plants are associated with the phytochemical constituents contained within them (Malabadi et al., 2021; Malabadi and Chalannavar, 2020; Ahirwar et al., 2020). However, further phytochemical evaluations in most of these kinds of studies are required to elucidate the antimicrobial effect with more accuracy as suggested by Khan et al. (2013). The results revealed that the rhizome extract of $C$. orchioides and fruit extracts of $S$. parviflorus have good antibacterial activity and can be tested further with specific trials to develop antibacterial drugs. For initial screening of medicinal plants for antibacterial activity is faster, more accurate and reliable with resazurin dye reduction method. 
Table 2. MIC values for different solvent extracts of medicinal plant parts used for screening antibacterial activity against selective bacteria by resazurin dye reduction assay.

\begin{tabular}{|c|c|c|c|c|c|c|c|c|c|c|}
\hline \multirow{3}{*}{$\begin{array}{l}\text { Plant } \\
\text { name }\end{array}$} & \multirow{3}{*}{$\begin{array}{l}\text { Extract of } \\
\text { the plant } \\
\text { part used }\end{array}$} & \multicolumn{9}{|c|}{ Minimum inhibitory concentration (MIC, in $\mu \mathrm{L})$} \\
\hline & & \multicolumn{3}{|c|}{ Staphylococcus aureus } & \multicolumn{3}{|c|}{ Pseudomonas aeruginosa } & \multicolumn{3}{|c|}{ Klebsiella pneumoniae } \\
\hline & & PET-E & METH & ETH & PET-E & METH & ETH & PET-E & METH & ETH \\
\hline $\mathrm{CS}$ & Leaf & $>1000$ & $>1000$ & 500 & $>1000$ & $>1000$ & 250 & $>1000$ & $>1000$ & 500 \\
\hline CS & Stem & $>1000$ & $>1000$ & $>1000$ & $>1000$ & $>1000$ & $>1000$ & $>1000$ & $>1000$ & $>1000$ \\
\hline PR & Leaf & $>1000$ & 500 & 500 & 500 & 500 & 250 & $>1000$ & $>1000$ & $>1000$ \\
\hline PR & Stem bark & 500 & 500 & 250 & $>1000$ & 500 & 500 & $>1000$ & $>1000$ & 500 \\
\hline AP & Leaf & $>1000$ & 500 & 500 & $>1000$ & $>1000$ & $>1000$ & $>1000$ & 500 & 500 \\
\hline AP & Stem & $>1000$ & $>1000$ & $>1000$ & $>1000$ & $>1000$ & $>1000$ & $>1000$ & $>1000$ & $>1000$ \\
\hline SE & Leaf & 500 & 500 & 250 & 250 & 250 & 500 & 500 & 500 & 250 \\
\hline SE & Fruit & 250 & 250 & 250 & 500 & 500 & 250 & 500 & 250 & 125 \\
\hline $\mathrm{CO}$ & Leaf & $>1000$ & $>1000$ & 500 & $>1000$ & $>1000$ & $>1000$ & 500 & $>1000$ & 500 \\
\hline $\mathrm{CO}$ & Rhizome & 500 & 250 & 125 & 500 & 125 & 125 & 500 & 500 & 250 \\
\hline SP & Leaf & $>1000$ & $>1000$ & 500 & $>1000$ & 500 & 500 & 500 & 250 & 250 \\
\hline SP & Fruit & 500 & 500 & 250 & 250 & 250 & 125 & 125 & 125 & 125 \\
\hline
\end{tabular}

Note: (A) Coleus strobilifer- CS; (B) Phyllanthus reticulates - PR; (C) Acalypha paniculata - AP; (D) Solanum erianthum - SE; (E) Curculigo orchioides - CO; (F) Spatholobus parviflorus - SP.

\section{Conflict of interest statement}

Authors declare that they have no conflict of interest.

\section{References}

Ahirwar, P. K., Mishra, S. P., Pramod Kumar, 2020. Comparative evaluation of phytochemicals in leaf, stem bark and root bark of Holarrhena antidysenterica, Wrightia tomentosa and Wrightia tinctoria. Int. J. Curr. Res. Biosci. Plant Biol., 7(10): 31-37.

Aslam, B., Wang, W., Arshad, M.I., Khurshid, M., Muzammil, S., Rasool, M.H., Nisar, M.A., Alvi, R.F., Aslam, M.A., Qamar, M.U. and Salamat, M.K.F., 2018. Antibiotic resistance: a rundown of a global crisis. Infect. Drug Resist., 11: 1645-1658.

Chauhan, N.S., Sharma, V., Thakur, M., Dixit, V.K., 2010. Curculigo orchioides: the black gold with numerous health benefits. J. Chin. Integr. Med., 8(7): 613-623.

IMP, 2021. Indian Medicinal Plants - Fact Sheet, National Medicinal Plants Board, Government of India. URL: https://www.nmpb.nic.in/content/ medicinal-plants-fact-sheet

Karuppusamy, S., Rajasekaran, K.M., 2009. High throughput antibacterial screening of plant extracts by resazurin redox with special reference to medicinal plants of Western Ghats. Global J. Pharmacol., 3(2): 63-68.

Kauroo, S., Govinden-Soulange, J., RanghooSanmukhiya, V.M., Miranda, K., Cotham, W.E., Walla, M.D., Nagarkatti, M. and Nagarkatti, P., 2021. Extracts of select endemic plants from the Republic of Mauritius exhibiting anti-cancer and immunomodulatory properties. Scient. Rep., 11(1): $1-17$.

Kausar, F., Farooqi, M.A., Farooqi, H.M.U., Salih, A.R.C., Khalil, A.A.K., Kang, C.W., Mahmoud, M.H., Batiha, G.E.S., Choi, K.H., Mumtaz, A.S., 2021. Phytochemical investigation, antimicrobial, antioxidant and anticancer activities of Acer cappadocicum Gled. Life, 11(7): 656.

Khan, U.A., Rahman, H., Niaz, Z., Qasim, M., Khan, J., Tayyaba, Rehman, B., 2013. Antibacterial activity of some medicinal plants against selected human pathogenic bacteria. Eur. J. Microbiol. Immunol., 3(4): 272-274.

Malabadi, R. B., Chalannavar, R. K., 2020. Safed musli (Chlorophytum borivilianum): Ethnobotany, phytochemistry and pharmacological updates. Int. J. Curr. Res. Biosci. Plant Biol., 7(11): 25-31.

Malabadi, R. B., Kolkar, K. A., Meti, N. T., Chalannavar, R. K., 2021. Recent updates on the 
role of herbal medicine for Alzheimer's disease (Dementia). Int. J. Curr. Res. Biosci. Plantbiol., 8(1): 14-45.

Shirsat, R. P., Imran, S., Koche, D. K., 2020. A report on identification of a unique hygrine like compound from chloroform extract of Anisochilus carnosus (L.f.) Wall. Drug Discovery, 14(33): 130-134.

Salehi, B., Gültekin-Özgüven, M., Kirkin, C., Özçelik, B., Morais-Braga, M.F.B., Carneiro, J.N.P., Bezerra, C.F., Silva, T.G.D., Coutinho, H.D.M., Amina, B. and Armstrong, L., 2020. Antioxidant, antimicrobial, and anticancer effects of anacardium plants: an ethnopharmacological perspective. Front.
Endocrinol., 11: 295.

Sharma, S., Kumar, S., 2013. Phyllanthus reticulatus Poir.-An important medicinal plant: A review of its phytochemistry, traditional uses and pharmacological properties. Int. J. Pharmaceut. Sci. Res., 4: 2528-2534.

Ventola, C.L., 2015. The antibiotic resistance crisis. Part 1: Causes and threats. Pharmacy and Therapeutics, 40(4): 277-283.

Yau, J.W., Thor, S.M., Tsai, D., Speare, T., Rissel, C., 2021. Antimicrobial stewardship in rural and remote primary health care: a narrative review. Antimicrob. Resist. Infect. Control, 10(1): 1-33.

\section{How to cite this article:}

Arivalagan, K. and Prakash, M. 2021. Rapid screening for minimum inhibitory concentration of medicinal plant extracts against human pathogenic bacteria. Int. J. Curr. Res. Biosci. Plant Biol., 8(6): 29-34.

doi: https://doi.org/10.20546/ijcrbp.2021.806.003 